\title{
Article
}

\section{The Effects of Butyrate on Induced Metabolic-Associated Fatty Liver Disease in Precision-Cut Liver Slices}

\author{
Grietje H. Prins ${ }^{1,+} \mathbb{D}$, Melany Rios-Morales ${ }^{2,+}$, Albert Gerding ${ }^{2,3}$, Dirk-Jan Reijngoud ${ }^{2}$, Peter Olinga ${ }^{1, *(D)}$ \\ and Barbara M. Bakker ${ }^{2, *}$
}

1 Department of Pharmaceutical Technology and Biopharmacy, University of Groningen, Groningen Research Institute of Pharmacy, A. Deusinglaan 1, 9713 AV Groningen, The Netherlands; g.g.h.prins@rug.nl

2 Laboratory of Pediatrics, Center for Liver, Digestive and Metabolic Diseases, University of Groningen, University Medical Center Groningen, A. Deusinglaan 1, 9713 AV Groningen, The Netherlands; m.y.rios.morales@umcg.nl (M.R.-M.); a.gerding@umcg.nl (A.G.); d.j.reijngoud01@umcg.nl (D.-J.R.)

3 Department of Laboratory Medicine, University of Groningen, University Medical Center Groningen, A. Deusinglaan 1, 9713 AV Groningen, The Netherlands

* Correspondence: P.Olinga@rug.nl (P.O.); B.M.Bakker01@umcg.nl (B.M.B.); Tel.: +31-50-36-38373 (P.O.); +31-50-36-11542 (B.M.B.)

+ These authors contributed equally to this work.

Citation: Prins, G.H.; Rios-Morales, M.; Gerding, A.; Reijngoud, D.-J.; Olinga, P.; Bakker, B.M. The Effects of Butyrate on Induced MetabolicAssociated Fatty Liver Disease in Precision-Cut Liver Slices. Nutrients 2021, 13, 4203. https://doi.org/ $10.3390 /$ nu13124203

Academic Editor: Antoni Sureda

Received: 13 October 2021

Accepted: 23 November 2021

Published: 24 November 2021

Publisher's Note: MDPI stays neutral with regard to jurisdictional claims in published maps and institutional affiliations.

Copyright: (c) 2021 by the authors. Licensee MDPI, Basel, Switzerland. This article is an open access article distributed under the terms and conditions of the Creative Commons Attribution (CC BY) license (https:// creativecommons.org/licenses/by/ $4.0 /)$.

\begin{abstract}
Metabolic-associated fatty liver disease (MAFLD) starts with hepatic triglyceride accumulation (steatosis) and can progress to more severe stages such as non-alcoholic steatohepatitis (NASH) and even cirrhosis. Butyrate, and butyrate-producing bacteria, have been suggested to reduce liver steatosis directly and systemically by increasing liver $\beta$-oxidation. This study aimed to examine the influence of butyrate directly on the liver in an ex vivo induced MAFLD model. To maintain essential intercellular interactions, precision-cut liver slices (PCLSs) were used. These PCLSs were prepared from male C57BL/6J mice and cultured in varying concentrations of fructose, insulin, palmitic acid and oleic acid, to mimic metabolic syndrome. Dose-dependent triglyceride accumulation was measured after 24 and $48 \mathrm{~h}$ of incubation with the different medium compositions. PCLSs viability, as indicated by ATP content, was not affected by medium composition or the butyrate concentration used. Under induced steatotic conditions, butyrate did not prevent triglyceride accumulation. Moreover, it lowered the expression of genes encoding for fatty acid oxidation and only increased C4 related carnitines, which indicate butyrate oxidation. Nevertheless, butyrate lowered the fibrotic response of PCLSs, as shown by reduced gene expression of fibronectin, alpha-smooth muscle actin and osteopontin, and protein levels of type I collagen. These results suggest that in the liver, butyrate alone does not increase lipid $\beta$-oxidation directly but might aid in the prevention of MAFLD progression to NASH and cirrhosis.
\end{abstract}

Keywords: MAFLD; NAFLD; butyrate; SCFA; steatosis; liver; fatty acid oxidation; fibrosis

\section{Introduction}

The first stage of metabolic-associated fatty liver disease (MAFLD, previously referred to as non-alcoholic fatty liver disease) is characterized by hepatic triglyceride accumulation, also known as steatosis [1]. While the pathology has surpassed a global prevalence of $25 \%$, this stage often goes unnoticed in patients [1,2]. It is the progression of the disease to an inflammatory state called non-alcoholic steatohepatitis and beyond, that places the more obvious burden on patients, healthcare and the economy [3,4]. As the hepatic manifestation of obesity, MAFLD is closely related to metabolic syndrome. Despite prevalence of and knowledge about the disease, there is still no appropriate treatment [2,5]. Therefore, potential strategies to ameliorate MAFLD should be investigated.

Consumption of a western diet, which is high in carbohydrates and fatty acids, is often considered to be the cause of metabolic syndrome [6]. This condition is characterized by reduced glucose tolerance, dyslipidaemia and insulin resistance [7]. This leads to an 
unregulated uptake of saccharides and fatty acids by the liver, by which hepatic lipogenesis is increased and fatty acid oxidation is reduced. This imbalance in lipid metabolism leads to hepatic steatosis [8].

Different from the dietary fatty acids, short-chain fatty acids (SCFA) are the product of fibre fermentation by the gut microbiota. These products, mainly acetate, propionate and butyrate, can be locally metabolised, or absorbed and transported to the liver for further metabolism [9]. High fibre intake has been linked to improvement of metabolic syndrome by reducing body weight, improving insulin sensitivity and increasing energy expenditure $[6,10,11]$.

Accumulating literature describes butyrate as a link between diet and metabolic health of the host. In patients, reduced levels of butyrate are associated with more advanced liver disease [12]. In rodents, a high-fat diet reduced butyrate production and increased levels of inflammation, hepatic steatosis and cholesterol [13]. Also in rodents, oral administration of butyrate or butyrate-producing bacteria decreased hepatic lipogenesis and increased $\beta$-oxidation [11] and prevented the onset of MAFLD and progression to NASH [11,14-16].

The beneficial effects on the liver of oral butyrate supplementation can be indirect due to inter-organ crosstalk, e.g., by butyrate stimulating GLP-1 secretion from the gut [17], improving the intestinal barrier [16,18], modulating the enterohepatic immune response [19], or by regulating adipose tissue metabolism $[10,20]$. Another option is that butyrate influences the liver directly, which has been less thoroughly studied. Butyrate can exert its effects in different ways. First, it can increase PPAR dependent signalling which leads to AMP-activated protein kinase (AMPK) phosphorylation, by which metabolism and inflammation are regulated $[13,19]$. This was shown to increase $\beta$-oxidation in HepG2 cells and in ex vivo mouse liver tissue [11]. Secondly, the SCFA can regulate gene transcription via inhibition of histone deacetylase proteins (HDACs) [21,22]. In this way, butyrate was able to enhance GLP-1R protein expression [23] and downregulate NF- $\mathrm{BB}$ transcription, which attenuated inflammation and fibrosis [24,25]. Lastly, butyrate can also be used as an energy substrate by the host. Butyrate can enter the mitochondria where it is oxidized to acetyl-CoA. The resulting molecule can be used for ATP production and also as a precursor for lipid synthesis $[26,27]$. The differential effects butyrate has on the coordination of lipid metabolism towards oxidation or synthesis, and the direct consequences this has on liver inflammation, need to be further addressed.

To investigate the direct effects of butyrate on the liver, studies often use simple cell cultures such as HepG2 cells [28]. In MAFLD development and progression, communication between different cell types is essential [4,29]. Many in vitro models lack the cellular interplay that is required to accurately mimic disease [30]. Precision-cut liver slices (PCLSs) retain the multicellular environment of the liver and have been used to study various diseases [31]. PCLSs have been thoroughly characterized as a fibrosis model [32,33]. A more recent study shows that it is possible to accumulate triglycerides in rat PCLSs, through reduced $\beta$-oxidation and increased de novo lipogenesis, in a pathophysiological manner [34]. Therefore, the aim of this study was to examine the liver-specific effects of butyrate on lipid metabolism in an ex vivo induced MAFLD-PCLSs model.

\section{Materials and Methods}

\subsection{Animals}

Male C57/BL6 mice (Centrale Dienst Proefdieren, UMCG, Groningen, The Netherlands), aged 9 to 12 weeks, were housed under standard conditions with water and chow ad libitum. Their body weight ranged from 22 to $32 \mathrm{~g}$. Livers from 16 mice were harvested after exsanguination under isoflurane $/ \mathrm{O}_{2}$ anaesthesia and stored in ice-cold organ preservation solution (University of Wisconsin). Cold ischaemia time was less than one hour. Experiments were approved by the Animal Ethical Committee of the University of Groningen. 


\subsection{Precision-Cut Liver Slices (PCLSs)}

PCLSs, with an estimated thickness of $\sim 250 \mu$ m, were prepared using a Krumdieck Tissue Slicer (Alabama Research and Development, Munford, AL, USA). PCLSs were cultured in different media at $37^{\circ} \mathrm{C}$ under continuous supply of $80 \% \mathrm{O}_{2}$ and $5 \% \mathrm{CO}_{2}$, as previously described [35]. PCLSs were cultured up to $48 \mathrm{~h}$ and culture medium was refreshed every $24 \mathrm{~h}$.

\subsection{Culture Media}

Williams medium E with Glutamax at $\mathrm{pH} 7.4$ (Invitrogen, Bleiswijk, The Netherlands), supplemented with gentamycin $(50 \mathrm{mg} / \mathrm{mL}$; Invitrogen) and L-carnitine $(1 \mathrm{mM}$, Sigma-Aldrich, St. Louis, MO, USA), was used as control medium. To mimic metabolic syndrome, a culture medium with additional supraphysiological concentrations (Table 1, unless indicated otherwise) of glucose (Merck, Darmstadt, Germany), fructose (Merck), human insulin (Sigma-Aldrich), palmitic acid and oleic acid (Sigma-Aldrich) was used. Concentrations were based on human serum concentrations [36,37] and in vivo rodent portal vein concentrations $[34,38]$ and optimised for this study.

Table 1. Composition of culture media.

\begin{tabular}{|c|c|c|c|c|c|c|}
\hline \multirow{2}{*}{ Medium } & \multirow{2}{*}{ Additives } & \multicolumn{5}{|c|}{ Final Concentration in Medium } \\
\hline & & Glucose & Fructose & Insulin & Palmitic Acid & Oleic Acid \\
\hline CTR & Glucose & $11 \mathrm{mM}$ & & & & \\
\hline GFI & Glucose, fructose, and insulin & $11 \mathrm{mM}$ & $5 \mathrm{mM}$ & $1 \mathrm{nM}$ & & \\
\hline GFIPO & $\begin{array}{l}\text { Glucose, fructose, insulin, } \\
\text { palmitic acid and oleic acid }\end{array}$ & $11 \mathrm{mM}$ & $1 \mathrm{mM}$ & $1 \mathrm{nM}$ & $120 \mu \mathrm{M}$ & $240 \mu \mathrm{M}$ \\
\hline
\end{tabular}

CTR = control; GFI = glucose, fructose and insulin; GFIPO = glucose, fructose, insulin, palmitic acid and oleic acid.

Palmitic acid and oleic acid were dissolved in $0.1 \mathrm{M}$ sodium hydroxide (Merck, Darmstadt, Germany) at $70{ }^{\circ} \mathrm{C}$, and then mixed with preheated $0.04 \%$ BSA solution (SigmaAldrich, St. Louis, MO, USA) at $55{ }^{\circ} \mathrm{C}$. The same concentration of BSA and sodium hydroxide was added to control media. Addition of this amount of BSA and sodium hydroxide did not affect medium $\mathrm{pH}$ and PCLS viability.

Sodium Butyrate (NaB; Sigma-Aldrich) and Sodium chloride ( $\mathrm{NaCl}$; Sigma-Aldrich) were dissolved in PBS (Gibco, ThermoFisher Scientific, Waltham, MA, USA). NaCl was used as a control for the $\mathrm{NaB}$ addition and is presented as $\mathrm{NaCl}$ throughout the paper to avoid confusion with the control medium CTR (Table 1). The concentration of $\mathrm{NaB}$ or $\mathrm{NaCl}$ in medium was $1 \mathrm{mM}$, unless specified otherwise.

\subsection{Triglyceride Quantitation}

For each condition, three precision-cut liver slices were pooled, snap-frozen and stored at $-80^{\circ} \mathrm{C}$. Subsequently, PCLSs were homogenized in $600 \mu \mathrm{L}$ Tris-buffered saline $(\sim 25 \mathrm{mg} / \mathrm{mL})$ by bead beating for $30 \mathrm{~s}$ at $5000 \mathrm{rpm}$ with 4 to $52.3 \mathrm{~mm}$ zirconium beads (Precellys 24, Bertin Technologies, Montigny Le Bretonneux, France) at $4{ }^{\circ} \mathrm{C}$. Fat was extracted using the Bligh \& Dyer method [39]. In short, samples were mixed in a glass tube with $1500 \mu \mathrm{L}$ of chloroform: methanol (2:1). Tubes were vortexed for $30 \mathrm{~min}$ at $4{ }^{\circ} \mathrm{C}$. Subsequently, $600 \mu \mathrm{L}$ of milliQ water and $500 \mu \mathrm{L}$ of chloroform were added, samples were vortexed for $5 \mathrm{~min}$ and centrifuged at $1500 \times \mathrm{g}$ for $10 \mathrm{~min}$. Of the chloroform layer, $900 \mu \mathrm{L}$ were moved into a new glass tube and dried under $\mathrm{N}_{2}$ stream. Lipids were dissolved in $150 \mu \mathrm{L}$ of $2 \%$ triton-X in chloroform, dried under $\mathrm{N}_{2}$ and dissolved in 150 milliQ $\mu \mathrm{L}$ water while shaking at $37^{\circ} \mathrm{C}$ in a water bath for $30 \mathrm{~min}$. Triglyceride content was determined using a Trig/GB kit (Roche Molecular Biochemicals, 11877771, Almere, The Netherlands) according to the protocol provided by the manufacturer. Values were calculated using a glycerol standard curve and normalized for protein content using the Pierce BCA Protein 
Assay Kit (ThermoFisher Scientific). Data are presented as percentage of the control $(\mathrm{CTR}) \pm$ SEM.

\subsection{Acylcarnitine Measurement}

Acylcarnitines are measured as a proxy for $\beta$-oxidation. For each condition, three precision-cut liver slices were pooled, snap-frozen and stored at $-80^{\circ} \mathrm{C}$. Subsequently, PCLSs were homogenized in $600 \mu \mathrm{L}$ tris-buffered saline $(\sim 25 \mathrm{mg} / \mathrm{mL})$ by bead beating for $30 \mathrm{~s}$ at $5000 \mathrm{rpm}$ with 4 to $52.3 \mathrm{~mm}$ zirconium beads at $4{ }^{\circ} \mathrm{C}$. In brief, $250 \mu \mathrm{L}$ of cold acetonitrile was added to $25 \mu \mathrm{L}$ of sample, shortly vortexed and then $250 \mu \mathrm{L}$ of internal standard (L-carnitine-[ $\left[\mathrm{D}_{3}\right]$, acetyl-L-carnitine-[ $\left.\mathrm{D}_{3}\right]$, propionyl-L-carnitine-[ $\left[\mathrm{D}_{3}\right]$, octanoylL-carnitine- $\left[\mathrm{D}_{3}\right]$, and palmitoyl-L-carnitine-[$\left[\mathrm{D}_{3}\right]$ ) was added to the mix. Subsequently, samples were vortexed again and centrifuged (RT, max speed $20,000 \times g$ ) for $10 \mathrm{~min}$. Finally, $150 \mu \mathrm{L}$ from each sample were transferred to an injection vial with insert for LCMS/MS analysis. Acylcarnitine quantification was normalized for protein content using the Pierce BCA Protein Assay Kit.

\subsection{ATP Determination}

Intracellular ATP content was measured to indicate viability. For each condition, individual precision-cut liver slices were collected in $1 \mathrm{~mL}$ of SONOP buffer (2 mM EDTA in $70 \%$ ethanol at $\mathrm{pH} 10.9)$, snap-frozen and stored at $-80^{\circ} \mathrm{C}$. ATP content was measured using a bioluminescence kit (Roche Diagnostics, Mannheim, Germany) as previously described [35]. Measured ATP was corrected for total protein content using a Lowry assay (BioRad DC Protein Assay, Hercules, CA, USA). Values for each group were expressed as a $(\Delta)$ percentage of the $48 \mathrm{~h}$ control $(\mathrm{CTR}$ or $\mathrm{NaCl}) \pm \mathrm{SEM}$.

\subsection{Release of Pro-Collagen $\operatorname{I\alpha } 1$}

As a measure of fibrosis, release of pro-collagen $\mathrm{I} \alpha 1$ was measured. Pooled culture medium from three PCLSs per condition per mouse was frozen at $-20^{\circ} \mathrm{C}$ and diluted tenfold. Levels of excreted protein were measured using the mouse Pro-Collagen I alpha 1 kit from (ab210579; Abcam, Cambridge, UK) according to instructions from the manufacturer. Values were normalized for total protein content using the Pierce BCA Protein Assay Kit.

\subsection{Quantitative Real-Time PCR}

To measure mRNA levels, three PCLSs were pooled per condition, snap-frozen in liquid nitrogen, and stored at $-80^{\circ} \mathrm{C}$. RNA was isolated using the RNeasy Lipid Tissue Mini Kit (Qiagen, Venlo, The Netherlands). The Reverse Transcription System (Promega, Leiden, The Netherlands) was used to reverse transcribe RNA. cDNA was amplified using SYBR Green Mixture (Bio-rad Laboratories, Veenendaal, The Netherlands). Primer sequences are displayed in Supplementary Table S1 (ThermoFisher Scientific). Gene symbols are presented in line with MGI guidelines.

Quantitative real-time PCR was performed using a QuantStudio ${ }^{\mathrm{TM}} 7$ Flex System (ThermoFisher Scientific). Thermal cycling started with a $10 \mathrm{~min}$ hold at $95^{\circ} \mathrm{C}$, followed by 40 cycles that consisted of $15 \mathrm{~s}$ at $95^{\circ} \mathrm{C}, 30 \mathrm{~s}$ at $60^{\circ} \mathrm{C}$, and $30 \mathrm{~s}$ at $72{ }^{\circ} \mathrm{C}$. $\mathrm{Ct}$ values were corrected for the $\mathrm{Ct}$ values of $\mathrm{Hmbs}$, which has previously been identified as a stable marker in the murine liver [40]. This yielded $\Delta \mathrm{Ct}$ values that were used to perform statistics and calculate $-\Delta \Delta \mathrm{Ct}$ values. Z-scores are used to present differential expression in heat maps $(n=5)$.

\subsection{Statistics}

Every experiment was performed at least as a biological triplicate, i.e., with PCLSs obtained from three different mice. Results are expressed as means \pm standard error of the mean (SEM) and compared to the control group. Individual values are shown as circles. Comparisons were made using a paired one-way ANOVA with Dunnett's post hoc analysis when GFI or GFIPO were compared to CTR medium, and a paired two-way ANOVA with 
Šídák's multiple comparison analysis when $\mathrm{NaB}$ was compared to $\mathrm{NaCl}$ (CTR, GFI or GFIPO). For the heat maps with only two groups a paired $t$-test was performed. Results were considered statistically significant when the calculated $p$-value was smaller than 0.05 .

\section{Results}

\subsection{Induction and Characterisation of Steatosis in PCLSs}

To study the direct effect of butyrate on early-stage MAFLD, this phenotype was first induced in healthy murine precision-cut liver slices. Culture of PCLSs with concentrations of $36 \mathrm{mM}$ glucose, $5 \mathrm{mM}$ fructose, $240 \mu \mathrm{M}$ palmitate, $480 \mu \mathrm{M}$ oleate and $100 \mathrm{nM}$ insulin (High-GFIPO; as previously used in rat PCLSs [34]), resulted in a 2-fold increase in triglyceride content after $48 \mathrm{~h}$ compared to the control medium (Supplementary Figure S1A). Besides the induction of steatosis, this condition substantially reduced intracellular ATP content, a measure of viability (Supplementary Figure S1B), possibly indicating that the quality of PCLSs deteriorated.

To induce steatosis and preserve viability with the minimum amount of energy substrates added, the concentrations of sugars and fatty acids were varied. There was no significant difference in triglyceride accumulation when the glucose concentration was decreased from the previously used $36 \mathrm{mM}$ to $11 \mathrm{mM}$ (Supplementary Figure S1A). After fructose titration, $1 \mathrm{mM}$ fructose was sufficient to achieve the maximum TG accumulation after 24 and $48 \mathrm{~h}$ (Supplementary Figure S2A,B). While the significance of TG accumulation did not depend on the concentration of palmitate and oleate, the accumulation was most reproducible when using $120 \mu \mathrm{M}$ and $240 \mu \mathrm{M}$, respectively (Supplementary Figure S2A,B). Moreover, fat accumulation was more reproducible after $48 \mathrm{~h}$ especially with $1 \mathrm{mM}$ fructose, thus PCLSs were cultured for $48 \mathrm{~h}$ in subsequent experiments.

After $48 \mathrm{~h}$ of incubation in the presence of glucose, fructose, insulin, palmitate and oleate (GFIPO, concentrations in Table 1), triglyceride levels were increased by $67 \%$ as compared to the control (Figure 1A). The significant increase in C14-C18 acylcarnitines confirmed that the supplied palmitate and oleate were taken up by PCLSs (Supplementary Table S2). To be able to differentiate between the effect of fatty acid influx and the effect of de novo lipogenesis, a condition with additional fructose $(5 \mathrm{mM})$ and no fatty acids (GFI, concentrations in Table 1) was added. This medium caused a smaller accumulation of triglycerides as compared to GFIPO medium (36\%, Figure 1A), suggesting that the fatty acid uptake makes a large contribution to the TG accumulation. Neither culture medium altered ATP significantly, indicating that these optimized steatosis-inducing media did not affect PCLSs viability (Figure 1B).

Compared to the condition with only glucose as an energy substrate (CTR), both the GFI and the GFIPO medium upregulated mRNA levels of genes encoding proteins involved in fatty acid synthesis and hexose uptake, namely elongation of very long chain fatty acids protein 6 (Elovl6), fatty acid synthase (Fasn), and glucose transporter 2 (Slc2a2) (Figure 1C, clusters 1 and 3). The condition with a higher fructose concentration, but no fatty acids (GFI) had a bigger impact on these genes, and additionally upregulated expression of acetyl-CoA carboxylase (Acaca) and Acyl-CoA desaturase (Scd) (Figure 1C, cluster 3). Besides, there was a marked decrease of genes encoding enzymes involved in oxidation of fatty acids, when they were analysed as a panel. The reduction of the cluster as a whole was significant with a $p$-value of $<0.05$ for GFIPO (Figure 1C, cluster 5). These data suggest that induction of steatosis in PCLSs relies also on de novo synthesis of lipids, more so in GFI than in GFIPO medium, together with reduced fatty acid catabolism. 
A

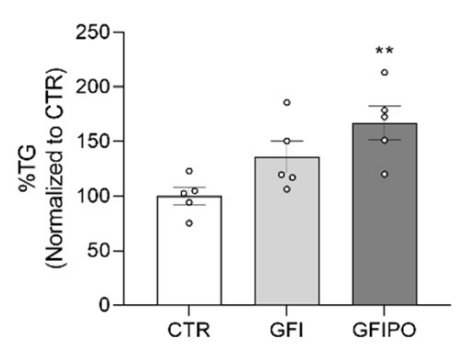

B

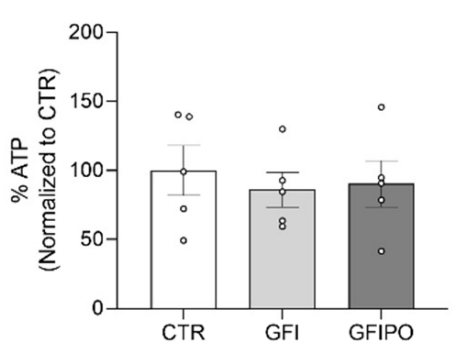

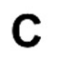

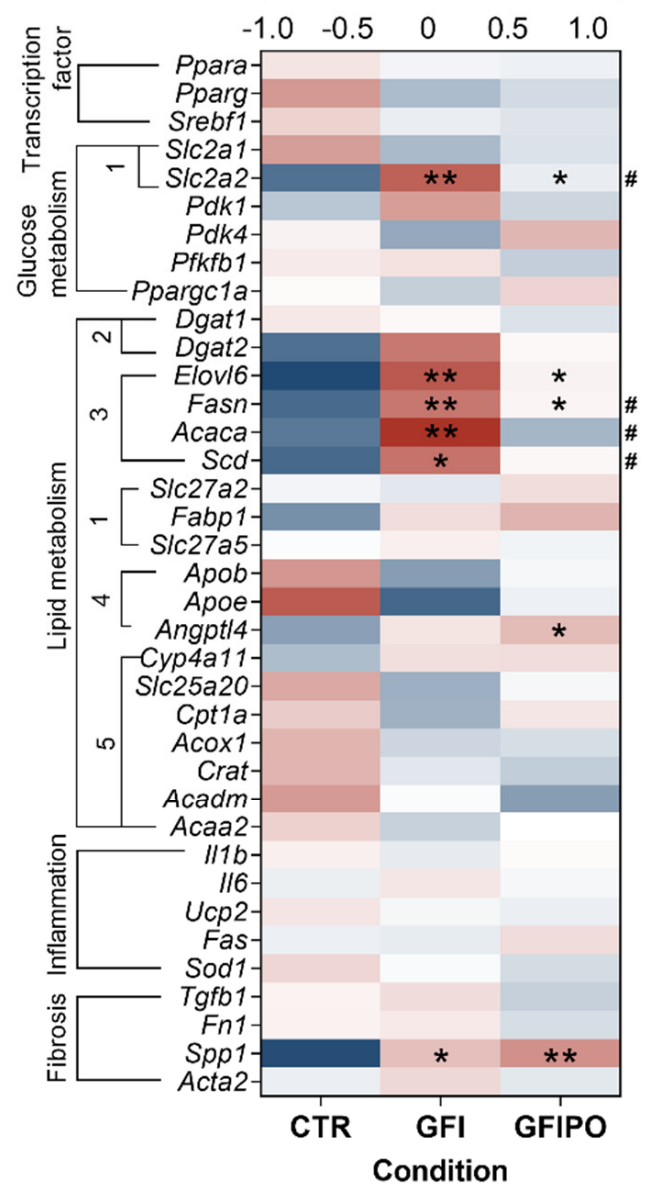

Figure 1. Induction and characterisation of steatosis in PCLS. (A) TG levels and (B) ATP concentration after $48 \mathrm{~h}$ incubation with GFI or GFIPO medium, compared to CTR. Data are presented as mean percentage \pm SEM. (C) Heat map of mRNA levels of genes encoding transcription factors, transporters (1) and enzymes (2: triglyceride assembly, 3: lipid synthesis, 4: FA efflux, 5: FA oxidation) involved in glucose and fatty acid metabolism, inflammation and fibrosis after $48 \mathrm{~h}$ incubation in CTR, GFI or GFIPO medium. Medium compositions were abbreviated according to Table 1 (CTR = control; GFI = glucose, fructose, and insulin; and GFIPO = GFI plus palmitic acid and oleic acid). Differential expression is presented using Z-scores (red: high Z-score, upregulated; blue: low Z-score, downregulated). ${ }^{*}=p<0.05,{ }^{* *}=p<0.01$ compared to CTR, $\#=p<0.05$ compared between GFI and GFIPO. Individual values are shown as circles.

Inflammation and fibrosis play an important role in the progression of MAFLD. Therefore, gene expression of markers of an inflammatory response and tissue remodelling were measured. Interestingly, neither medium affected inflammation at the mRNA level. Media did cause an increased gene expression of osteopontin (Spp1), a marker of fibrosis [41], indicating that there might be tissue remodelling and fibrosis. In conclusion, both GFI and GFIPO media induce steatosis but do not instigate an inflammatory response at the mRNA level.

\subsection{Effects of Butyrate Treatment on Fatty Acid and Triglyceride Synthesis}

Butyrate has been found to decrease hepatic fat accumulation in vivo [10]. To test whether this could be a direct effect of butyrate, it was assessed whether butyrate prevented triglyceride accumulation when PCLSs were incubated with sugars and lipids. Triglyceride content was not affected by $1 \mathrm{mM}$ butyrate in either GFI or GFIPO medium (Figure 2A). A higher concentration of butyrate $(3 \mathrm{mM})$ rather tended to increase TG levels (Supplementary 
Figure S3A). Transcript levels of genes involved in glucose metabolism and lipid synthesis were not regulated by butyrate in the control medium (Figure 2B). In GFI medium fatty acid binding protein 1 (Fabp1), involved in hepatic fatty acid transport and metabolism [42], was increased by butyrate (Figure 2C). In GFIPO medium, mRNAs encoding proteins in fatty acid synthesis, Elovl6 and Fasn, were significantly reduced by butyrate (Figure 2D). These were among the genes that were upregulated by GFIPO medium originally.
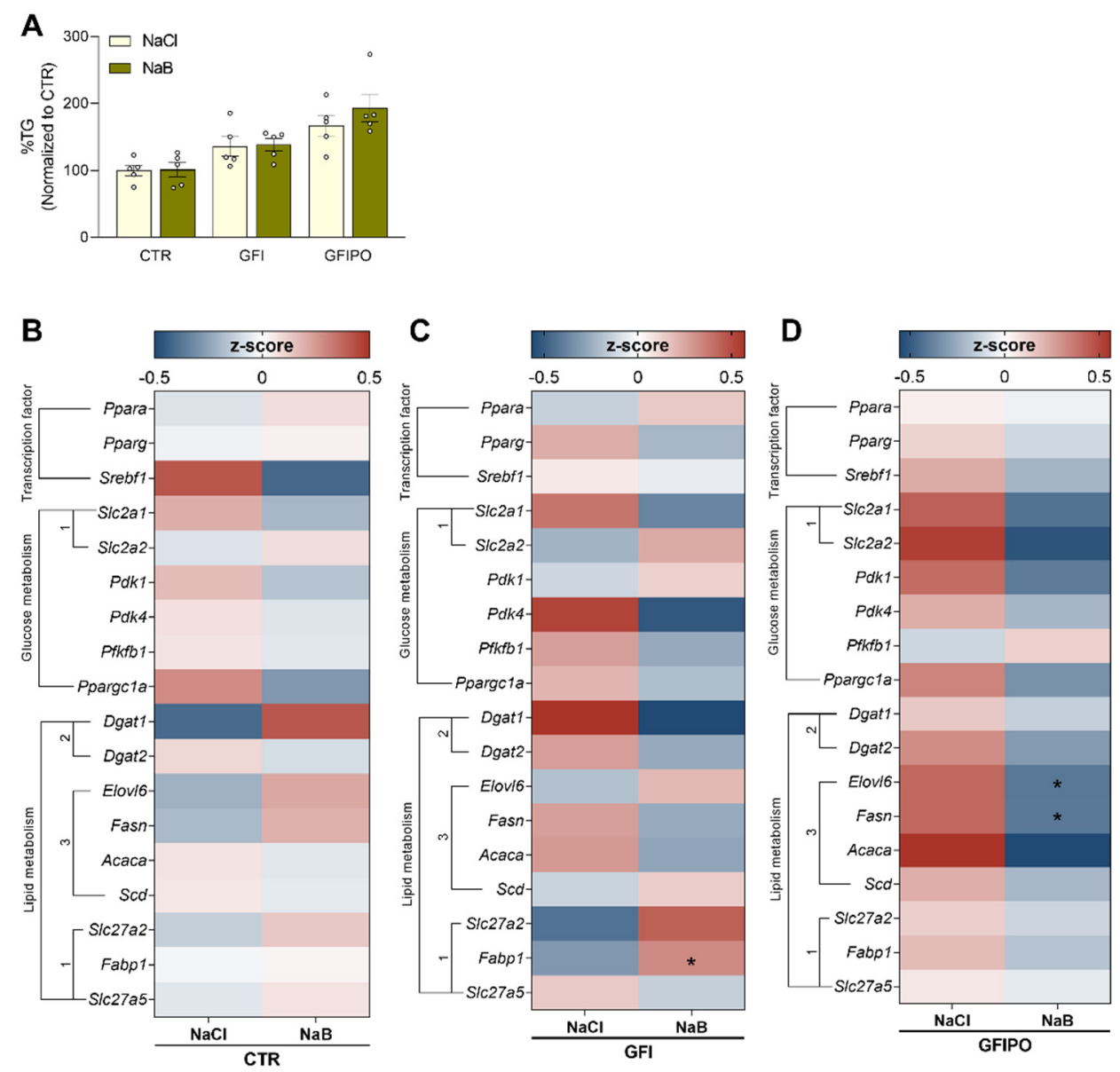

Figure 2. Effects of butyrate treatment on triglyceride accumulation and metabolism. (A) Relative TG levels in the three different media with $1 \mathrm{mM} \mathrm{NaCl}$ (control) or $1 \mathrm{mM} \mathrm{NaB}$ (sodium butyrate). Data are presented as mean percentage of control \pm SEM. (B-D) Heat maps of measured mRNA expression levels of genes related to lipid and glucose metabolism after culture in (B) CTR medium, (C) GFI medium, (D) GFIPO medium with $1 \mathrm{mM} \mathrm{NaCl}$ or $1 \mathrm{mM} \mathrm{NaB}$. Medium compositions were abbreviated according to Table $1(\mathrm{CTR}=$ control; GFI = glucose, fructose, and insulin; and GFIPO = GFI plus palmitic acid and oleic acid). Differential expression is presented using Z-scores (red: high Z-score, upregulated; blue: low Z-score, downregulated). ${ }^{*}=p<0.05$ compared to $\mathrm{NaCl}$. Individual values are shown as circles.

This suggests that in GFIPO butyrate tended to downregulate fatty acid synthesis, but the effect may have been overruled by the overload of substrates, including the butyrate itself. This could explain why TG levels were not affected by butyrate, while fatty acid synthesis genes were downregulated.

\subsection{Effects of Butyrate Treatment on Clearance and Oxidation of Fatty Acids}

To investigate the effects of butyrate on lipid clearance and oxidation, mRNA levels of genes involved in these processes were measured (Figure 3). Minor differences were seen for genes involved in lipid efflux. While apolipoprotein expression remained unaffected by butyrate in all conditions, mRNA levels of the lipoprotein lipase activity mediator Angptl4 
were significantly increased in CTR medium (Figure 3A), and slightly reduced in GFI and GFIPO medium (Figure 3B,C).
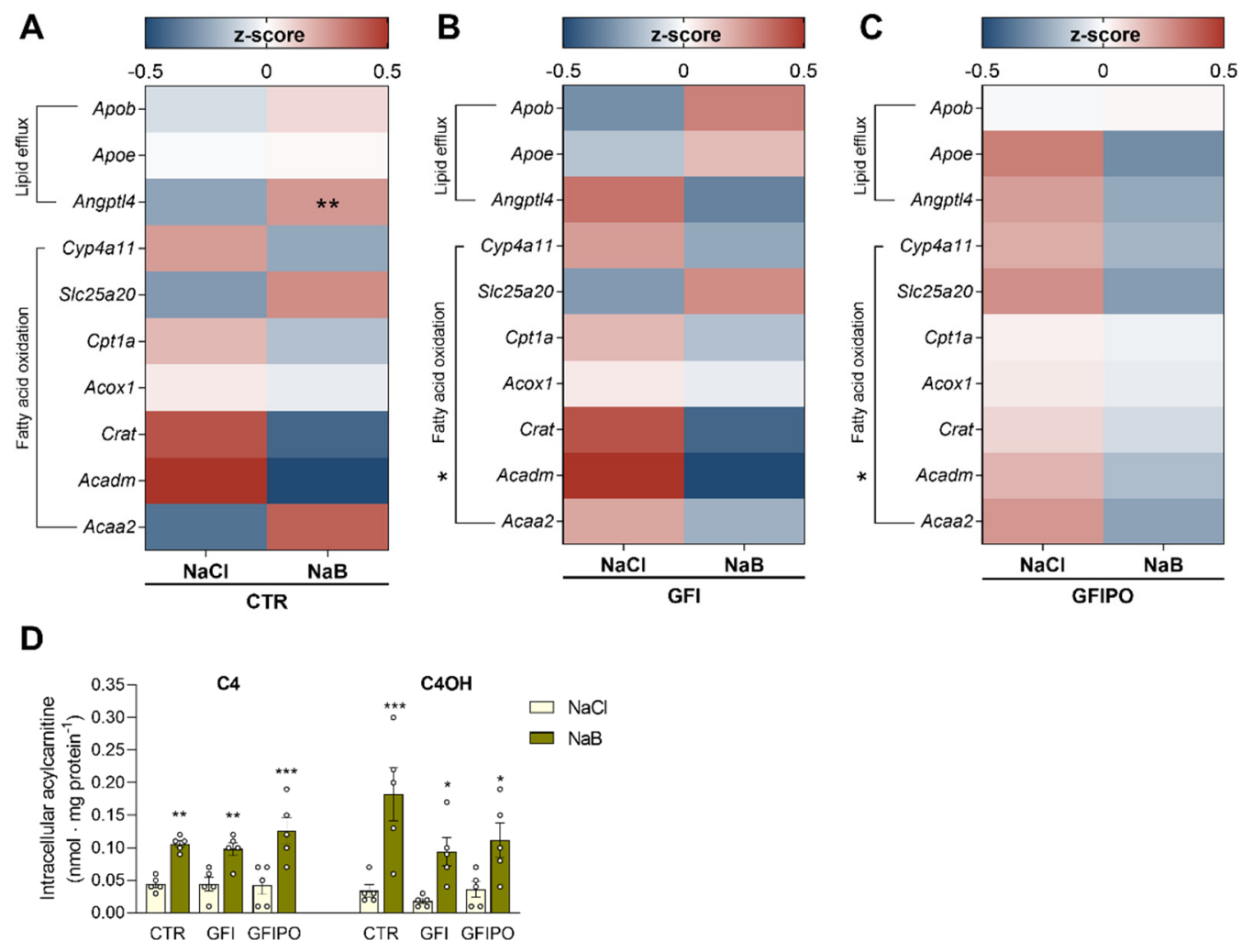

Figure 3. Effects of butyrate treatment on clearance and oxidation of fatty acids. Heat map of measured expression levels of genes related to lipid efflux (Apob, Apoe and Angptl4) and genes related to fatty acid oxidation (Slc25a20, Pdk4, Cyp4a11, Crat, Acox1, Acadm and Cpt1) after culture in (A) CTR medium, (B) GFI medium, (C) GFIPO medium with $1 \mathrm{mM} \mathrm{NaCl}$ (control) or $1 \mathrm{mM} \mathrm{NaB}$ (butyrate). Medium compositions were abbreviated according to Table 1 (CTR = control; GFI = glucose, fructose, and insulin; and GFIPO = GFI plus palmitic acid and oleic acid). Differential expression is presented using Z-scores (red: high Z-score, upregulated; blue: low Z-score, downregulated). (D) Intracellular butyrylcarnitine (C4) and hydroxybutyrylcarnitine $(\mathrm{C} 4 \mathrm{OH})$ quantification in CTR, GFI and GFIPO with $1 \mathrm{mM} \mathrm{NaCl}$ or $1 \mathrm{mM} \mathrm{NaB}$. Data are presented as mean $\pm \mathrm{SEM} .{ }^{*}=p<0.05,{ }^{* *}=p<0.01$, $* * *=p<0.001$ compared to $\mathrm{NaCl}$. Individual values are shown as circles.

Butyrate did not exert significant effects on any of the individual genes coding for enzymes involved in fatty acid oxidation, although a trend of downregulation was visible at the level of the entire cluster. When these genes were assessed as a panel, treatment with butyrate resulted in a significant reduction in GFI and GFIPO medium $(p<0.05$, Figure 3B,C).

Since fatty acids are esterified to carnitine before they are oxidized, acylcarnitine concentrations may be considered as a proxy for ongoing $\beta$-oxidation. To functionally assess $\beta$-oxidation, the profile of acylcarnitines was measured in the PCLSs. Long-chain fatty acids such as palmitate (C16:0) and oleate (C18:1) are activated and converted to acylcarnitines by carnitine palmitoyltransferase 1 (CPT1) to be able to enter the mitochondrial $\beta$-oxidation pathway [43]. Palmitate and oleate addition in the GFIPO condition increased the overall carnitine profile (Supplementary Figure S3B and Supplementary Table S2). Butyrate specifically increased butyrylcarnitine $(\mathrm{C} 4)$ and hydroxybutyrylcarnitine $(\mathrm{C} 4 \mathrm{OH})$ in all conditions, but did not alter the long-chain acylcarnitines. This demonstrates that butyrate is metabolized in the PCLSs, but does not affect the oxidation of long-chain fatty acids (Figure 3D, Supplementary Figure S3B and Supplementary Table S2). Acetylcarnitine 
(C2) levels were not significantly changed by either medium and only had a trend to increase with butyrate (Supplementary Figure S3C). Together the gene-expression and acylcarnitine levels show that butyrate is metabolised by the PCLSs, but does not affect long-chain fatty acid oxidation nor lipid efflux.

\subsection{The Effect of Butyrate on Inflammation and Tissue Remodelling}

Since inflammation and fibrosis play a crucial role in the progression of MAFLD, the effects of butyrate on these processes were examined (Figure $4 \mathrm{~A}-\mathrm{C}$ ). Both UCP2 and SOD1 are known to play a role in lipid metabolism as well as oxidative stress, and are linked to the development of NASH [44,45]. Butyrate treatment resulted in a trend of downregulation of $U c p 2$, Sod1, and death receptor Fas (not to be confused with fatty-acid synthase Fasn), but not of interleukins $1 \beta$ and 6 which are more specific for inflammation. Differences in the regulation of fibrosis genes were more pronounced. Butyrate reduced the expression of fibrosis-related mRNAs in all media (with $p$-values of $<0.18,0.01$ and 0.07 for CTR, GFI and GFIPO, respectively) (Figure 4A-C). These changes in fibrotic markers were confirmed by pro-collagen I $\alpha 1$ secretion, a functional measure of fibrosis (Figure $4 \mathrm{D}$ ). This secretion was not significantly altered by the GFI or GFIPO media. Butyrate, however, lowered the levels of pro-collagen $\mathrm{I} \alpha 1$ in all conditions, up to an average reduction of $67 \pm 14 \%$ in CTR culture medium. Viability, assessed as ATP content, was not affected by butyrate (Figure 4E). Together, these data suggest that fibrosis in PCLCs is reduced by butyrate supplementation.

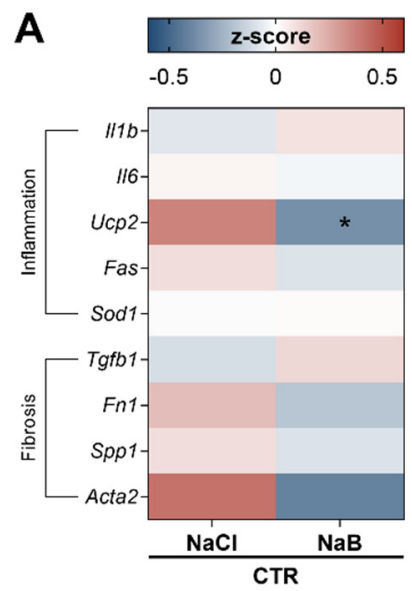

D

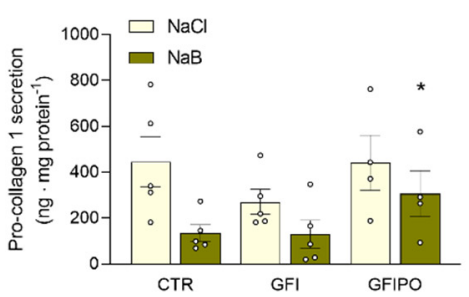

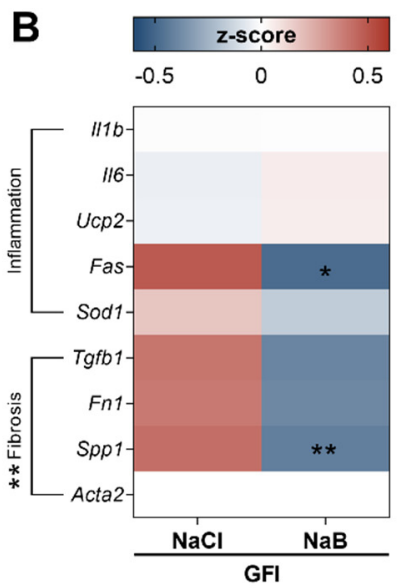

E
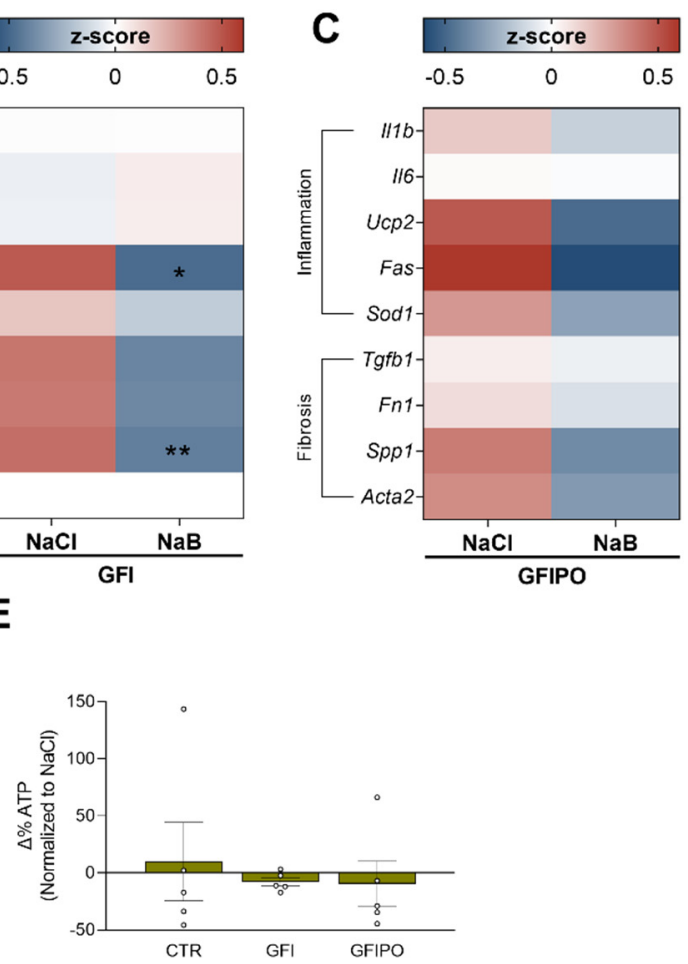

Figure 4. Effects of butyrate on inflammation and tissue remodelling. (A-C) Heat maps displaying mRNA expression of genes indicative of inflammation $(I l 1 b, I l 6, U c p 2$, Fas, Sod1) and genes related to tissue remodelling (Tgfb1, Fn1, Spp1, Acta2) after culture in (A) CTR medium, (B) GFI medium, (C) GFIPO medium with $1 \mathrm{mM} \mathrm{NaCl}$ (control) or $1 \mathrm{mM} \mathrm{NaB} \mathrm{(butyrate).}$ Differential expression is presented using Z-scores (red: high Z-score, upregulated; blue: low Z-score, downregulated). (D) Excreted pro-collagen I $\alpha 1$ after culture in CTR, GFI and GFIPO medium with $1 \mathrm{mM} \mathrm{NaCl}$ or $1 \mathrm{mM}$ NaB. (E) Difference in intracellular ATP content after culture with $\mathrm{NaB}$ as compared to $\mathrm{NaCl}$. Medium compositions were abbreviated according to Table 1 (CTR = control; GFI = glucose, fructose, and insulin; and GFIPO = GFI plus palmitic acid and oleic acid). Data are presented as mean $\pm \mathrm{SEM}^{*}=p<0.05,{ }^{* *}=p<0.01$ compared to $\mathrm{NaCl}$. Individual values are shown as circles. 


\section{Discussion}

To study MAFLD, the PCLS model is a promising tool that recapitulates the multicellular architecture of the liver. This technique supports the 3Rs of Replacement, Reduction and Refinement of animal use [46,47], since multiple conditions can be tested in the same liver. In this paper, steatosis was first induced in healthy murine liver slices. The minimum concentrations of glucose, fructose, insulin and fatty acids that resulted in robust induction of steatosis without loss of viability were identified. Steatosis could be attributed to a combination of de novo lipogenesis, fatty acid uptake and reduced fatty acid oxidation. Butyrate did not prevent steatosis, but reduced fibrosis, an important characteristic of MAFLD progression.

Overconsumption of sugars and fat contributes to hepatic steatosis [8,48,49]. Fructose is particularly lipogenic, since in contrast to glucose, it is metabolized by the liver in an unregulated fashion [50,51]. The products pyruvate and acetyl-CoA are used as substrates for de novo lipogenesis, which is increased in MAFLD patients [8,52]. In addition, dietary long-chain fatty acids, such as palmitate and oleate, can be elongated and stored in the liver as triglycerides $[53,54]$. In this study, steatosis was induced by supplementation of $11 \mathrm{mM}$ glucose, $1 \mathrm{mM}$ fructose, $100 \mathrm{nM}$ insulin and a mixture of $0.36 \mathrm{mM}$ palmitate and oleate (GFIPO) and by the omission of fatty acids while increasing to $5 \mathrm{mM}$ fructose (GFI). In comparison, fructose plasma concentrations depend strongly on diet but can reach well over $5 \mathrm{mM}$ (humans) and $1 \mathrm{mM}$ (rodents) [38,55], and the free fatty acid concentration up to $1 \mathrm{mM}$ [56-58]. These may be even higher in the portal vein, as indicated by previous measurements in rodents [38,59]. Since fructose is a substrate for de novo lipogenesis [8], it is not surprising that the GFI medium elicited the highest upregulation of lipogenic gene expression. Progression of human MAFLD is characterized by inflammation and fibrosis [3,60]. Fibrosis could be attributed to palmitate-related lipotoxicity [61] or fructoserelated ATP depletion [62]. No inflammatory response was measured in PCLSs, but this could possibly be instigated by addition an inflammatory stimulus like lipopolysaccharide, which is elevated in MAFLD patients $[63,64]$. The fact that the PCLSs showed a fibrotic response, but no inflammatory response, suggests that they mimic early-stage MAFLD.

In vivo supplementation of butyrate or butyrate-producing bacteria alleviate features of metabolic syndrome, including hepatic steatosis and fibrosis [11-16]. Butyrate can act as a regulator, inducing fatty acid oxidation and reducing lipogenesis [11,14], but it is also a precursor for de novo lipogenesis as shown by the administration of labelled butyrate [26]. The use of PCLSs allowed to investigate the direct effect on liver tissue, as opposed to the indirect effects via cross-talk with other organs. The concentrations used in this study were in the high physiological range $(1 \mathrm{mM})$, to avoid depletion due to metabolism. In comparison, plasma butyrate concentrations are typically in the micromolar range $[20,65,66]$. However, plasma butyrate reached transient $\mathrm{mM}$ concentrations in mice that were fed with butyrate [67] and again, portal vein concentrations could be higher, but measurements are scarce. In agreement with in vivo studies [26,68], we found that butyrate served as a metabolic substrate, inferred here by the elevated $\mathrm{C} 4$ and $\mathrm{C} 4 \mathrm{OH}$ carnitine levels in the butyrate groups. This could lead to an increase in acetyl-CoA, which may explain why butyrate did not decrease, but rather increased TG accumulation in the PCLSs. Moreover, in contrast to in vivo studies [11] and HepG2 cells [24], butyrate reduced mRNA levels of proteins involved in fatty acid oxidation in PCLSs. The mRNA levels of lipogenesis genes Elovl6 and Fasn were decreased by butyrate only in the GFIPO and not in the GFI condition. The counteracting effects of butyrate as a regulator and as a substrate for lipogenesis is of high interest when developing butyrate as an intervention for metabolic disease. The fact that butyrate elicits a decrease in steatosis in vivo [11], but not in PCLSs, suggests that the regulatory role of butyrate can be a consequence of inter-organ crosstalk. Reported effects of butyrate include decreased lipolysis in the adipose tissue which prevents the excess of lipid supply to other organs $[10,69]$ and increased GLP-1 and PYY secretion from the gut, which regulates food intake and satiety $[10,17]$. 
In mice with advanced MAFLD, butyrate reduced the mRNA levels of inflammatory genes Ilb and Il6 [15,16,70]. That this was not recapitulated in PCLSs, may be attributed to the fact that inflammation was anyway low in this in vitro model. The difference between in vivo results and PCLSs may be due to the absence of circulating immune cells, such as monocytes and infiltrating macrophages, that present G-protein coupled receptors that can bind butyrate $[70,71]$. Therefore, the in vivo effects might have derived from organ interplay, and not from direct liver effects. In contrast, the PCLSs exhibited signs of fibrosis, a typical feature of MAFLD [3]. These were alleviated by butyrate. The key players in liver fibrosis are hepatic stellate cells (HSCs) [72], which produce $\alpha$-smooth muscle actin $(\alpha \mathrm{SMA} ;$ Acta2) and other extracellular matrix components. Limited studies confirm that butyrate can attenuate rat HSC activation, thereby lowering the expression of collagens and aSMA [73]. This effect is seen in vivo and in fresh primary HSCs, but understandably not in HepG2 cells as they cannot produce collagen $[14,74]$. The presence of HSCs in PCLSs [75] may explain the anti-fibrotic effects of butyrate in this study.

\section{Conclusions}

In conclusion, murine PCLSs treated with insulin, carbohydrates and fatty acids recapitulate key features of early-stage MAFLD, making them a promising ex vivo model for the disease. The intact tissue structure of the precision-cut liver slices makes them particularly a good model to study mechanisms underlying steatosis, fibrosis and potential treatments. The translational value of this model would be even greater when human liver tissue is used. In the present ex vivo model butyrate did not reduce steatosis, suggesting that butyrate was mostly used as a substrate for lipogenesis under the investigated culture conditions. These contradictory effects of butyrate will be of relevance for clinical studies in which liver concentrations of butyrate are increased.

Supplementary Materials: The following are available online at https:/ /www.mdpi.com/article/ 10.3390/nu13124203/s1, Figure S1: Investigation of substrate additives in PCLSs, Figure S2: The effect of fructose and fatty acid supplementation on triglyceride accumulation, Figure S3: The effect of butyrate on triglyceride accumulation and acylcarnitine profile, Table S1: List of oligonucleotide primer pairs used in qPCR analysis, Table S2: Acylcarnitine quantification.

Author Contributions: Conceptualization, M.R.-M., G.H.P., B.M.B., D.-J.R., P.O.; investigation, G.H.P., M.R.-M.; methodology, M.R.-M., G.H.P., A.G.; visualization, G.H.P., M.R.-M.; formal analysis, M.R.-M., G.H.P.; resources, P.O., B.M.B.; writing—original draft preparation, G.H.P., M.R.-M.; writing - review and editing, B.M.B., D.-J.R., P.O.; supervision, B.M.B., D.-J.R., P.O.; funding acquisition, P.O., D.-J.R. and B.M.B. All authors have read and agreed to the published version of the manuscript.

Funding: D.-J.R. and M.R.-M. received funding from the UMCG Hereditary Metabolic Diseases Fund.

Institutional Review Board Statement: Experiments were approved by the Animal Ethical Committee of the University of Groningen (Permit number 171290-01-001).

Informed Consent Statement: Not applicable.

Data Availability Statement: Not applicable.

Conflicts of Interest: The authors declare no conflict of interest.

\section{References}

1. Fabbrini, E.; Sullivan, S.; Klein, S. Obesity and nonalcoholic fatty liver disease: Biochemical, metabolic and clinical implications. Hepatology 2010, 51, 679-689. [CrossRef] [PubMed]

2. Younossi, Z.M.; Loomba, R.; Rinella, M.E.; Bugianesi, E.; Marchesini, G.; Neuschwander-Tetri, B.A.; Serfaty, L.; Negro, F.; Caldwell, S.H.; Ratziu, V.; et al. Current and future therapeutic regimens for nonalcoholic fatty liver disease and nonalcoholic steatohepatitis. Hepatology 2018, 68, 361-371. [CrossRef] [PubMed]

3. Younossi, Z.; Anstee, Q.M.; Marietti, M.; Hardy, T.; Henry, L.; Eslam, M.; George, J.; Bugianesi, E. Global burden of NAFLD and NASH: Trends, predictions, risk factors and prevention. Nat. Rev. Gastroenterol. Hepatol. 2018, 15, 11-20. [CrossRef] 
4. Machado, M.V.; Diehl, A.M. Pathogenesis of nonalcoholic steatohepatitis. Gastroenterology 2016, 150, 1769-1777. [CrossRef] [PubMed]

5. Ferguson, D.; Finck, B.N. Emerging therapeutic approaches for the treatment of NAFLD and type 2 diabetes mellitus. Nat. Rev. Endocrinol. 2021, 17, 484-495. [CrossRef] [PubMed]

6. Berná, G.; Romero-Gomez, M. The role of nutrition in non-alcoholic fatty liver disease: Pathophysiology and management. Liver Int. 2020, 40, 102-108. [CrossRef]

7. Khan, R.S.; Bril, F.; Cusi, K.; Newsome, P.N. Modulation of insulin resistance in nonalcoholic fatty liver disease. Hepatology 2019, 70, 711-724. [CrossRef]

8. Schwarz, J.M.; Linfoot, P.; Dare, D.; Aghajanian, K. Hepatic de novo lipogenesis in normoinsulinemic and hyperinsulinemic subjects consuming high-fat, low-carbohydrate and low-fat, high-carbohydrate isoenergetic diets. Am. J. Clin. Nutr. 2003, 77, 43-50. [CrossRef]

9. Bloemen, J.G.; Venema, K.; van de Poll, M.C.; Olde Damink, S.W.; Buurman, W.A.; Dejong, C.H. Short chain fatty acids exchange across the gut and liver in humans measured at surgery. Clin. Nutr. 2009, 28, 657-661. [CrossRef] [PubMed]

10. Canfora, E.E.; Jocken, J.W.; Blaak, E.E. Short-chain fatty acids in control of body weight and insulin sensitivity. Nat. Rev. Endocrinol. 2015, 11, 577-591. [CrossRef] [PubMed]

11. Den Besten, G.; Bleeker, A.; Gerding, A.; Van Eunen, K.; Havinga, R.; Van Dijk, T.H.; Oosterveer, M.H.; Jonker, J.W.; Groen, A.K.; Reijngoud, D.J.; et al. Short-chain fatty acids protect against high-fat diet-induced obesity via a pparg-dependent switch from lipogenesis to fat oxidation. Diabetes 2015, 64, 2398-2408. [CrossRef] [PubMed]

12. Juanola, O.; Ferrusquía-Acosta, J.; García-Villalba, R.; Zapater, P.; Magaz, M.; Marín, A.; Olivas, P.; Baiges, A.; Bellot, P.; Turon, F.; et al. Circulating levels of butyrate are inversely related to portal hypertension, endotoxemia, and systemic inflammation in patients with cirrhosis. FASEB J. 2019, 33, 11595-11605. [CrossRef]

13. Jakobsdottir, G.; Xu, J.; Molin, G.; Ahrné, S.; Nyman, M. High-fat diet reduces the formation of butyrate, but increases succinate, inflammation, liver fat and cholesterol in rats, while dietary fibre counteracts these effects. PLoS ONE 2013, 8, e80476. [CrossRef] [PubMed]

14. Endo, H.; Niioka, M.; Kobayashi, N.; Tanaka, M.; Watanabe, T. Butyrate-producing probiotics reduce nonalcoholic fatty liver disease progression in rats: New insight into the probiotics for the gut-liver axis. PLoS ONE 2013, 8, e63388. [CrossRef]

15. Mattace Raso, G.; Simeoli, R.; Russo, R.; Iacono, A.; Santoro, A.; Paciello, O.; Ferrante, M.C.; Canani, R.B.; Calignano, A.; Meli, R. Effects of sodium butyrate and its synthetic amide derivative on liver inflammation and glucose tolerance in an animal model of steatosis induced by high fat diet. PLoS ONE 2013, 8, e68626. [CrossRef]

16. Ye, J.; Lv, L.; Wu, W.; Li, Y.; Shi, D.; Fang, D.; Guo, F.; Jiang, H.; Yan, R.; Ye, W.; et al. Butyrate protects mice against methioninecholine-deficient diet-induced non-alcoholic steatohepatitis by improving gut barrier function, attenuating inflammation and reducing endotoxin levels. Front. Microbiol. 2018, 9, 1967. [CrossRef]

17. Kaji, I.; Karaki, S.I.; Kuwahara, A. Short-chain fatty acid receptor and its contribution to glucagon-like peptide-1 release. Digestion 2014, 89, 31-36. [CrossRef]

18. Zhou, D.; Pan, Q.; Xin, F.Z.; Zhang, R.N.; He, C.X.; Chen, G.Y.; Liu, C.; Chen, Y.W.; Fan, J.G. Sodium butyrate attenuates high-fat diet-induced steatohepatitis in mice by improving gut microbiota and gastrointestinal barrier. World J. Gastroenterol. 2017, 23, 60-75. [CrossRef] [PubMed]

19. Zhou, D.; Pan, Q.; Liu, X.L.; Yang, R.X.; Chen, Y.W.; Liu, C.; Fan, J.G. Clostridium butyricum B1 alleviates high-fat diet-induced steatohepatitis in mice via enterohepatic immunoregulation. J. Gastroenterol. Hepatol. 2017, 32, 1640-1648. [CrossRef]

20. Blaak, E.E.; Canfora, E.E.; Theis, S.; Frost, G.; Groen, A.K.; Mithieux, G.; Nauta, A.; Scott, K.; Stahl, B.; van Harsselaar, J.; et al. Short chain fatty acids in human gut and metabolic health. Benef. Microbes 2020, 11, 411-455. [CrossRef]

21. Davie, J.R. Inhibition of histone deacetylase activity by butyrate. J. Nutr. 2003, 133, 2485S-2493S. [CrossRef] [PubMed]

22. Ye, J.; Wu, W.; Li, Y.; Li, L. Influences of the gut microbiota on DNA methylation and histone modification. Dig. Dis. Sci. 2017, 62, 1155-1164. [CrossRef] [PubMed]

23. Zhou, D.; Chen, Y.W.; Zhao, Z.H.; Yang, R.X.; Xin, F.Z.; Liu, X.L.; Pan, Q.; Zhou, H.; Fan, J.G. Sodium butyrate reduces high-fat diet-induced non-alcoholic steatohepatitis through upregulation of hepatic GLP-1R expression. Exp. Mol. Med. 2018, 50, 1-12. [CrossRef]

24. Pirozzi, C.; Lama, A.; Annunziata, C.; Cavaliere, G.; De Caro, C.; Citraro, R.; Russo, E.; Tallarico, M.; Iannone, M.; Ferrante, M.C.; et al. Butyrate prevents valproate-induced liver injury: In vitro and in vivo evidence. FASEB J. 2020, 34, 676-690. [CrossRef]

25. Tayyeb, J.Z.; Popeijus, H.E.; Mensink, R.P.; Konings, M.C.J.M.; Mokhtar, F.B.A.; Plat, J. Short-chain fatty acids (Except hexanoic acid) lower NF-kB transactivation, which rescues inflammation-induced decreased apolipoprotein A-I transcription in HepG2 cells. Int. J. Mol. Sci. 2020, 21, 5088. [CrossRef] [PubMed]

26. Den Besten, G.; Lange, K.; Havinga, R.; van Dijk, T.H.; Gerding, A.; van Eunen, K.; Müller, M.; Groen, A.K.; Hooiveld, G.J.; Bakker, B.M.; et al. Gut-derived short-chain fatty acids are vividly assimilated into host carbohydrates and lipids. Am. J. Physiol. Gastrointest. Liver Physiol. 2013, 305, G900-G910. [CrossRef]

27. Astbury, S.M.; Corfe, B.M. Uptake and metabolism of the short-chain fatty acid butyrate, a critical review of the literature. Curr. Drug Metab. 2012, 13, 815-821. [CrossRef]

28. Soret, P.-A.; Magusto, J.; Housset, C.; Gautheron, J. In vitro and in vivo models of non-alcoholic fatty liver disease (NAFLD): A Critical Appraisal. J. Clin. Med. 2021, 10, 36. [CrossRef] 
29. Magee, N.; Zou, A.; Zhang, Y. Pathogenesis of nonalcoholic steatohepatitis: Interactions between liver parenchymal and nonparenchymal cells. BioMed Res. Int. 2016, 2016, 5170402. [CrossRef]

30. Kanuri, G.; Bergheim, I. In vitro and in vivo models of non-alcoholic fatty liver disease (NAFLD). Int. J. Mol. Sci. 2013, 14, 11963-11980. [CrossRef]

31. Westra, I.M.; Mutsaers, H.A.M.; Luangmonkong, T.; Hadi, M.; Oosterhuis, D.; de Jong, K.P.; Groothuis, G.M.M.; Olinga, P. Human precision-cut liver slices as a model to test antifibrotic drugs in the early onset of liver fibrosis. Toxicol. Vitro 2016, $35,77-85$. [CrossRef] [PubMed]

32. Bigaeva, E.; Gore, E.; Mutsaers, H.A.M.; Oosterhuis, D.; Kim, Y.O.; Schuppan, D.; Bank, R.A.; Boersema, M.; Olinga, P. Exploring organ-specific features of fibrogenesis using murine precision-cut tissue slices. BBA-Mol. Basis Dis. 2020, 1866, 165582. [CrossRef] [PubMed]

33. Vatakuti, S.; Olinga, P.; Pennings, J.L.A.; Groothuis, G.M.M. Validation of precision-cut liver slices to study drug-induced cholestasis: A transcriptomics approach. Arch. Toxicol. 2017, 91, 1401-1412. [CrossRef] [PubMed]

34. Prins, G.; Luangmonkong, T.; Oosterhuis, D.; Mutsaers, H.; Dekker, F.; Olinga, P. A pathophysiological model of non-alcoholic fatty liver disease using precision-cut liver slices. Nutrients 2019, 11, 507. [CrossRef]

35. De Graaf, I.A.M.; Olinga, P.; De Jager, M.H.; Merema, M.T.; De Kanter, R.; Van De Kerkhof, E.G.; Groothuis, G.M.M. Preparation and incubation of precision-cut liver and intestinal slices for application in drug metabolism and toxicity studies. Nat. Protoc. 2010, 5, 1540-1551. [CrossRef]

36. Bhatt, H.B.; Smith, R.J. Fatty liver disease in diabetes mellitus. Hepatobiliary Surg. Nutr. 2015, 4, 101-108. [CrossRef] [PubMed]

37. Hazlehurst, J.M.; Woods, C.; Marjot, T.; Cobbold, J.F.; Tomlinson, J.W. Non-alcoholic fatty liver disease and diabetes. Metabolism 2016, 65, 1096-1108. [CrossRef]

38. Patel, C.; Sugimoto, K.; Douard, V.; Shah, A.; Inui, H.; Yamanouchi, T.; Ferraris, R.P. Effect of dietary fructose on portal and systemic serum fructose levels in rats and in $\mathrm{KHK}^{-/-}$and GLUT5 ${ }^{-/-}$mice. Am. J. Physiol. Gastrointest. Liver Physiol. 2015, 309, G779-G790. [CrossRef]

39. Bligh, E.G.; Dyer, W.J. A rapid method of total lipid extraction and purification. Can. J. Biochem. Physiol. 1959, 37, 911-917. [CrossRef]

40. Gong, H.; Sun, L.; Chen, B.; Han, Y.; Pang, J.; Wu, W.; Qi, R.; Zhang, T. Evaluation of candidate reference genes for RT-qPCR studies in three metabolism related tissues of mice after caloric restriction. Sci. Rep. 2016, 6, 38513. [CrossRef]

41. Wen, Y.; Jeong, S.; Xia, Q.; Kong, X. Role of osteopontin in liver diseases. Int. J. Biol. Sci. 2016, 12, 1121-1128. [CrossRef] [PubMed]

42. Lu, Y.C.; Chang, C.C.; Wang, C.P.; Hung, W.C.; Tsai, I.T.; Tang, W.H.; Wu, C.C.; Wei, C.T.; Chung, F.M.; Lee, Y.J.; et al. Circulating fatty acid-binding protein 1 (FABP1) and nonalcoholic fatty liver disease in patients with type 2 diabetes mellitus. Int. J. Med. Sci. 2020, 17, 182-190. [CrossRef] [PubMed]

43. Eaton, S. Control of mitochondrial $\beta$-oxidation flux. Prog. Lipid Res. 2002, 41, 197-239. [CrossRef]

44. Serviddio, G.; Bellanti, F.; Tamborra, R.; Rollo, T.; Capitanio, N.; Romano, A.D.; Sastre, J.; Vendemiale, G.; Altomare, E. Uncoupling protein-2 (UCP2) induces mitochondrial proton leak and increases susceptibility of non-alcoholic steatohepatitis (NASH) liver to ischaemia-reperfusion injury. Gut 2008, 57, 957-965. [CrossRef] [PubMed]

45. Boland, M.L.; Oldham, S.; Boland, B.B.; Will, S.; Lapointe, J.M.; Guionaud, S.; Rhodes, C.J.; Trevaskis, J.L. Nonalcoholic steatohepatitis severity is defined by a failure in compensatory antioxidant capacity in the setting of mitochondrial dysfunction. World J. Gastroenterol. 2018, 24, 1748-1765. [CrossRef] [PubMed]

46. Dewyse, L.; Reynaert, H.; van Grunsven, L.A. Best practices and progress in precision-cut liver slice cultures. Int. J. Mol. Sci. 2021, 22, 3137. [CrossRef]

47. Fontana, F.; Figueiredo, P.; Martins, J.P.; Santos, H.A. Requirements for animal experiments: Problems and challenges. Small 2021, 17, 2004182. [CrossRef]

48. Softic, S.; Cohen, D.E.; Kahn, C.R. Role of dietary fructose and hepatic de novo lipogenesis in fatty liver disease. Dig. Dis. Sci. 2016, 61, 1282-1293. [CrossRef] [PubMed]

49. Van Herck, M.A.; Vonghia, L.; Francque, S.M. Animal models of nonalcoholic fatty liver disease-A starter's guide. Nutrients 2017, 9, 72. [CrossRef] [PubMed]

50. Berg, J.M.; Tymoczko, J.L.; Gatto, G.J.; Stryer, L. Biochemistry, 8th ed.; W. H. Freeman and Company: New York, NY, USA, 2015; pp. $467-468$.

51. Vos, M.B.; Lavine, J.E. Dietary fructose in nonalcoholic fatty liver disease. Hepatology 2013, 57, 2525-2531. [CrossRef]

52. Maersk, M.; Belza, A.; Stødkilde-Jørgensen, H.; Ringgaard, S.; Chabanova, E.; Thomsen, H.; Pedersen, S.B.; Astrup, A.; Richelsen, B. Sucrose-sweetened beverages increase fat storage in the liver, muscle, and visceral fat depot: A 6-mo randomized intervention study. Am. J. Clin. Nutr. 2012, 95, 283-289. [CrossRef] [PubMed]

53. Duarte, J.A.G.; Carvalho, F.; Pearson, M.; Horton, J.D.; Browning, J.D.; Jones, J.G.; Burgess, S.C. A high-fat diet suppresses de novo lipogenesis and desaturation but not elongation and triglyceride synthesis in mice. J. Lipid Res. 2014, 55, 2541-2553. [CrossRef] [PubMed]

54. Raatz, S.K.; Bibus, D.; Thomas, W.; Kris-Etherton, P. Human nutrition and metabolism: Total fat intake modifies plasma fatty acid composition in humans. J. Nutr. 2001, 131, 231-234. [CrossRef] [PubMed]

55. Kawasaki, T.; Akanuma, H.; Yamanouchi, T. Increased fructose concentrations in blood and urine in patients with diabetes. Diabetes Care 2002, 25, 353-357. [CrossRef] [PubMed] 
56. Maggs, D.G.; Buchanan, T.A.; Burant, C.F.; Cline, G.; Gumbiner, B.; Hsueh, W.A.; Inzucchi, S.; Kelley, D.; Nolan, J.; Olefsky, J.M.; et al. Metabolic effects of troglitazone monotherapy in type 2 diabetes mellitus. A randomized, double-blind, placebo-controlled trial. Ann. Intern. Med. 1998, 128, 176-185. [CrossRef]

57. Spiller, S.; Blüher, M.; Hoffmann, R. Plasma levels of free fatty acids correlate with type 2 diabetes mellitus. Diabetes Obes. Metab. 2018, 20, 2661-2669. [CrossRef]

58. Bhatt, N.M.; Aon, M.A.; Tocchetti, C.G.; Shen, X.; Dey, S.; Ramirez-Correa, G.; O'Rourke, B.; Gao, W.D.; Cortassa, S. Restoring redox balance enhances contractility in heart trabeculae from type 2 diabetic rats exposed to high glucose. Am. J. Physiol. Heart Circ. Physiol. 2015, 308, H291-H302. [CrossRef]

59. Matveyenko, A.V.; Veldhuis, J.D.; Butler, P.C. Measurement of pulsatile insulin secretion in the rat: Direct sampling from the hepatic portal vein. Am. J. Physiol. Endocrinol. Metab. 2008, 295, E569-E574. [CrossRef]

60. Younossi, Z.M.; Loomba, R.; Anstee, Q.M.; Rinella, M.E.; Bugianesi, E.; Marchesini, G.; Neuschwander-Tetri, B.A.; Serfaty, L.; Negro, F.; Caldwell, S.H.; et al. Diagnostic modalities for nonalcoholic fatty liver disease, nonalcoholic steatohepatitis, and associated fibrosis. Hepatology 2018, 68, 349-360. [CrossRef]

61. Ogawa, Y.; Imajo, K.; Honda, Y.; Kessoku, T.; Tomeno, W.; Kato, S.; Fujita, K.; Yoneda, M.; Saito, S.; Saigusa, Y.; et al. Palmitateinduced lipotoxicity is crucial for the pathogenesis of nonalcoholic fatty liver disease in cooperation with gut-derived endotoxin. Sci. Rep. 2018, 8, 11365. [CrossRef]

62. Abdelmalek, M.F.; Suzuki, A.; Guy, C.; Unalp-Arida, A.; Colvin, R.; Johnson, R.J.; Diehl, A.M.; Network, N.S.C.R. Increased fructose consumption is associated with fibrosis severity in patients with NAFLD. Hepatology 2010, 51, 1961-1971. [CrossRef] [PubMed]

63. Ceccarelli, S.; Panera, N.; Mina, M.; Gnani, D.; De Stefanis, C.; Crudele, A.; Rychlicki, C.; Petrini, S.; Bruscalupi, G.; Agostinelli, L.; et al. LPS-induced TNF- $\alpha$ factor mediates pro-inflammatory and pro-fibrogenic pattern in non-alcoholic fatty liver disease. Oncotarget 2015, 6, 41434-41452. [CrossRef] [PubMed]

64. Kolodziejczyk, A.A.; Zheng, D.; Shibolet, O.; Elinav, E. The role of the microbiome in NAFLD and NASH. EMBO Mol. Med. 2019, 11, e9302. [CrossRef] [PubMed]

65. Cummings, J.H.; Pomare, E.W.; Branch, H.W.J.; Naylor, C.P.E.; MacFarlane, G.T. Short chain fatty acids in human large intestine, portal, hepatic and venous blood. Gut 1987, 28, 1221-1227. [CrossRef] [PubMed]

66. Frampton, J.; Murphy, K.G.; Frost, G.; Chambers, E.S. Short-chain fatty acids as potential regulators of skeletal muscle metabolism and function. Nat. Metab. 2020, 2, 840-848. [CrossRef]

67. Egorin, M.J.; Yuan, Z.-M.; Sentz, D.L.; Plaisance, K.; Eiseman, J.L. Plasma pharmacokinetics of butyrate after intravenous administration of sodium butyrate or oral administration of tributyrin or sodium butyrate to mice and rats. Cancer Chemother. Pharmacol. 1999, 43, 445-453. [CrossRef]

68. Boets, E.; Gomand, S.V.; Deroover, L.; Preston, T.; Vermeulen, K.; De Preter, V.; Hamer, H.M.; Van den Mooter, G.; De Vuyst, L.; Courtin, C.M.; et al. Systemic availability and metabolism of colonic-derived short-chain fatty acids in healthy subjects: A stable isotope study. J. Physiol. 2017, 595, 541-555. [CrossRef]

69. Jocken, J.W.E.; Hernández, M.A.G.; Hoebers, N.T.H.; van der Beek, C.M.; Essers, Y.P.G.; Blaak, E.E.; Canfora, E.E. Short-chain fatty acids differentially affect intracellular lipolysis in a human white adipocyte model. Front. Endocrinol. 2018, 8, 372. [CrossRef] [PubMed]

70. Ang, Z.; Er, J.Z.; Tan, N.S.; Lu, J.; Liou, Y.C.; Grosse, J.; Ding, J.L. Human and mouse monocytes display distinct signalling and cytokine profiles upon stimulation with FFAR2/FFAR3 short-chain fatty acid receptor agonists. Sci. Rep. 2016, 6, 34145. [CrossRef] [PubMed]

71. Thangaraju, M.; Cresci, G.A.; Liu, K.; Ananth, S.; Gnanaprakasam, J.P.; Browning, D.D.; Mellinger, J.D.; Smith, S.B.; Digby, G.J.; Lambert, N.A.; et al. GPR109A is a G-protein-coupled receptor for the bacterial fermentation product butyrate and functions as a tumor suppressor in colon. Cancer Res. 2009, 69, 2826-2832. [CrossRef]

72. Khanam, A.; Saleeb, P.G.; Kottilil, S. Pathophysiology and treatment options for hepatic fibrosis: Can it be completely cured? Cells 2021, 10, 1097. [CrossRef] [PubMed]

73. Niki, T.; Rombouts, K.; De Bleser, P.; De Smet, K.; Rogiers, V.; Schuppan, D.; Yoshida, M.; Gabbiani, G.; Geerts, A. A histone deacetylase inhibitor, trichostatin A, suppresses myofibroblastic differentiation of rat hepatic stellate cells in primary culture. Hepatology 1999, 29, 858-867. [CrossRef] [PubMed]

74. Cook, K.J. Sodium Propionate and Sodium Butyrate Promote Fatty Acid Oxidation in HepG2 Cells under Oxidative Stress. Ph.D. Thesis, Louisiana State University, Baton Rouge, LA, USA, 2014; pp. 29-62.

75. Van de Bovenkamp, M.; Groothuis, G.M.M.; Meijer, D.K.F.; Slooff, M.J.H.; Olinga, P. Human liver slices as an in vitro model to study toxicity-induced hepatic stellate cell activation in a multicellular milieu. Chem. Biol. Interact. 2006, 162, 62-69. [CrossRef] [PubMed] 